\title{
New examples of self-catenation in two three-dimensional polymeric co-ordination networks $\dagger$
}

\author{
Lucia Carlucci, ${ }^{a}$ Gianfranco Ciani, ${ }^{* b}$ Davide M. Proserpio ${ }^{b}$ and Silvia Rizzato ${ }^{b}$ \\ ${ }^{a}$ Dipartimento di Biologia Strutturale e Funzionale, Università dell'Insubria, Via J. H. Dunant 3, \\ 21100 Varese, Italy \\ ${ }^{b}$ Dipartimento di Chimica Strutturale e Stereochimica Inorganica and Centro CNR, \\ Via G. Venezian 21, 20133 Milano, Italy
}

Received 17th April 2000, Accepted 16th June 2000

First published as an Advance Article on the web 29th September 2000

\begin{abstract}
Among the new types of entanglements in polymeric architectures the phenomenon of self-interpenetration has attracted attention in recent times. Two new three-dimensional networks that present this unusual topological feature have been obtained. The first species, $\left[\mathrm{Ag}(2 \text {-ethpyz) })_{2}\right]\left[\mathrm{SbF}_{6}\right] \mathbf{1}$ (2-ethpyz = 2-ethylpyrazine), contains four-connected silver centres that give $\left[\mathrm{Ag}_{4}(2 \text {-ethpyz })_{4}\right]$ squares linked into double-crankshaft ribbons. Each of these ribbons is joined to parallel identical motifs to form a three-dimensional four-connected binodal frame of $\left(4^{2}, 6^{3}, 8\right)\left(4^{2}, 6,8^{2}, 9\right)$ topology, the same as that of coesite, a high-pressure polymorph of silica, exhibiting self-catenated 8-membered circuits. The second species, $\left[\mathrm{Cu}(\mathrm{bpe})_{2}\left(\mathrm{SO}_{4}\right)\right] \cdot 5 \mathrm{H}_{2} \mathrm{O} 2$ [bpe $=1$,2-bis(4-pyridyl)ethane], is a nanoporous polymer based on copper(II) centres four-connected to pyridyl groups to give a $\left[\mathrm{Cu}(\mathrm{bpe})_{2}\right]$ three-dimensional binodal network with the unprecedented $\left(6^{4}, 8^{2}\right)\left(6,8^{5}\right)$ topology, showing the unique feature that all the shortest circuits are self-catenated.
\end{abstract}

\section{Introduction}

Polymeric co-ordination networks ${ }^{1}$ are of great current interest not only for their potential applications as new zeolite-like materials $^{2}$ for molecular selection, ion exchange and catalysis, but also for their intriguing architectures and topologies. Many recent examples have evidenced that topological types unprecedented in inorganic compounds and in minerals can be observed within co-ordination polymer frameworks. ${ }^{3}$ Particularly attractive is the finding of species with novel modes of supramolecular intertwining, that contribute more and more to increase our knowledge of the self-assembly processes and of the supramolecular self-organization of co-ordination polymers. The structural complexity of such systems needs a rational classification ${ }^{4}$ both of the topology of the constituent polymeric frames and of the interpenetration phenomena (type and degree), as a basic tool for the crystal engineering and for a better understanding of the properties of these materials. Interpenetrating networks ${ }^{5}$ are known to include a variety of types, ranging from $n$-fold entanglements of two-dimensional or three-dimensional frames with common prototypical topologies to more unusual species, like polymeric rotaxanes ${ }^{6}$ and polycatenated motifs. ${ }^{7}$ In this context, we have found particularly interesting a recent paper by the Robson group ${ }^{3 b}$ that reports a remarkable three-connected single network of $\left(12^{3}\right)$ topology, previously enumerated by Wells ${ }^{8}$ but never found in real species, that exhibits the peculiar feature of selfentanglement, in the sense that $1 / 3$ of the shortest circuits (12gons) starting and ending at one centre have other such circuits, referred to another centre, passing through them. Another more recent case, described as a 'polyknotted' network, involves interpenetrating one-dimensional ladder-like polymers that are connected by $\mu-\eta^{2}$-bridging nitrate counter ions to give a

$\dagger$ Based on the presentation given at Dalton Discussion No. 3, 9-11th September 2000, University of Bologna, Italy.

Electronic supplementary information (ESI) available: rotatable 3-D crystal structure diagram in CHIME format. See http://www.rsc.org/ suppdata/dt/b0/b003092i/ single four-connected uninodal frame of $\left(4^{2}, 6,8^{3}\right)$ topology. ${ }^{9}$ We have observed the same phenomenon of self-catenation in two novel three-dimensional single networks, obtained from the self-assembly of $\mathrm{AgSbF}_{6}$ with 2-ethylpyrazine (2-ethpyz) and of $\mathrm{CuSO}_{4} \cdot 5 \mathrm{H}_{2} \mathrm{O}$ with 1,2-bis(4-pyridyl)ethane (bpe), namely $\left[\mathrm{Ag}(2 \text {-ethpyz })_{2}\right]\left[\mathrm{SbF}_{6}\right] \mathbf{1}$ and $\left[\mathrm{Cu}(\mathrm{bpe})_{2}\left(\mathrm{SO}_{4}\right)\right] \cdot 5 \mathrm{H}_{2} \mathrm{O} \mathbf{2}$, respectively. We report here the synthesis and crystal structures of compounds $\mathbf{1}$ and $\mathbf{2}$, that, though belonging to different families of co-ordination polymers, share this unusual topological feature. It is noteworthy that $\mathbf{1}$ exhibits the topology of coesite, a high-pressure polymorph of silica, recognized by O'Keeffe to be 'unique among nets found in nature in that it contains 8-circuits that are linked as in a chain'. ${ }^{10}$

\section{Results and discussion}

Compound $\mathbf{1}$ is a silver(I) polymeric species assembled with a 'relatively short' linear exo-bidentate pyrazine spacer. We have already shown that pyrazine and substituted pyrazines are suitable for the self-assembly of co-ordination networks, and have reported on some interesting species obtained with different silver salts, including a threefold interpenetrated net with the $\alpha-\mathrm{ThSi}_{2}\left(10^{3}-\mathrm{b}\right)$ topology, ${ }^{11}$ a simple $\alpha$-polonium frame, ${ }^{12}$ and a remarkable 'solid-state racemate' exhibiting the $\mathrm{SrSi}_{2}\left(10^{3}-\mathrm{a}\right)$ topology. ${ }^{13}$ Since the network structure is strongly dependent both on the anion of the silver salt and on the substituents on the aromatic pyrazine ring, we are studying other self-assembly reactions of this type by a systematic variation of the reagents.

The reaction of $\mathrm{AgSbF}_{6}$ with 2-ethylpyrazine in $\mathrm{CH}_{2} \mathrm{Cl}_{2}$ using a molar ratio of $1: 2$ gives a mixture of products containing as the main species $\left[\mathrm{Ag}(2 \text {-ethpyz })_{2}\right]\left[\mathrm{SbF}_{6}\right] 1$. Crystalline samples obtained by slow diffusion methods show large multifacetted colourless single crystals of 1 together with minor amounts of flat crystals of a second product, characterized by single crystal X-ray analysis as the polymeric $\left[\mathrm{Ag}_{2}(2-\right.$ ethpyz $\left.)_{3}\right]\left[\mathrm{SbF}_{6}\right]_{2}$, that is comprised of two-dimensional layers of hexagonal meshes. ${ }^{14}$ The nature of the bulk precipitate has been investigated by X-ray powder diffraction techniques, by 
Table 1 Selected bond distances $(\AA)$ and angles $\left(^{\circ}\right)$ in compounds 1 and 2

\begin{tabular}{|c|c|c|c|}
\hline \multicolumn{4}{|l|}{ Compound 1} \\
\hline $\operatorname{Ag}(1)-N(14)$ & $2.420(8)$ & $\operatorname{Ag}(3)-N(44)$ & $2.246(7)$ \\
\hline $\operatorname{Ag}(1)-N(21)$ & $2.362(7)$ & $\operatorname{Ag}(3)-N(51)$ & $2.368(8)$ \\
\hline $\operatorname{Ag}(1)-N(34 A)$ & $2.469(6)$ & $\operatorname{Ag}(3)-N(64)$ & $2.377(8)$ \\
\hline $\operatorname{Ag}(1)-N(41)$ & $2.302(7)$ & $\operatorname{Ag}(3)-N(74)$ & $2.383(7)$ \\
\hline $\operatorname{Ag}(2)-N(24)$ & $2.525(8)$ & $\operatorname{Ag}(4)-N(11)$ & $2.315(7)$ \\
\hline $\operatorname{Ag}(2)-N(31 A)$ & $2.415(6)$ & $\operatorname{Ag}(4)-\mathrm{N}(54)$ & $2.408(8)$ \\
\hline $\operatorname{Ag}(2)-N(61)$ & $2.329(8)$ & $\operatorname{Ag}(4)-N(71)$ & $2.394(8)$ \\
\hline $\operatorname{Ag}(2)-N(81)$ & $2.253(6)$ & $\operatorname{Ag}(4)-N(84)$ & $2.300(7)$ \\
\hline $\mathrm{N}(14)-\mathrm{Ag}(1)-\mathrm{N}(34 \mathrm{~A})$ & $102.8(2)$ & $\mathrm{N}(44)-\mathrm{Ag}(3)-\mathrm{N}(51)$ & $123.8(3)$ \\
\hline $\mathrm{N}(21)-\mathrm{Ag}(1)-\mathrm{N}(14)$ & $92.5(3)$ & $\mathrm{N}(44)-\mathrm{Ag}(3)-\mathrm{N}(64)$ & $109.7(3)$ \\
\hline $\mathrm{N}(21)-\mathrm{Ag}(1)-\mathrm{N}(34 \mathrm{~A})$ & $96.8(2)$ & $\mathrm{N}(44)-\mathrm{Ag}(3)-\mathrm{N}(74)$ & $125.4(3)$ \\
\hline $\mathrm{N}(41)-\mathrm{Ag}(1)-\mathrm{N}(21)$ & $132.0(3)$ & $\mathrm{N}(51)-\mathrm{Ag}(3)-\mathrm{N}(64)$ & $100.4(3)$ \\
\hline $\mathrm{N}(41)-\mathrm{Ag}(1)-\mathrm{N}(14)$ & $110.5(3)$ & $\mathrm{N}(51)-\mathrm{Ag}(3)-\mathrm{N}(74)$ & $91.0(3)$ \\
\hline $\mathrm{N}(41)-\mathrm{Ag}(1)-\mathrm{N}(34 \mathrm{~A})$ & $116.9(2)$ & $\mathrm{N}(64)-\mathrm{Ag}(3)-\mathrm{N}(74)$ & $102.1(3)$ \\
\hline $\mathrm{N}(31 \mathrm{~A})-\mathrm{Ag}(2)-\mathrm{N}(24)$ & $100.6(2)$ & $\mathrm{N}(11)-\mathrm{Ag}(4)-\mathrm{N}(54)$ & $97.7(3)$ \\
\hline $\mathrm{N}(61)-\mathrm{Ag}(2)-\mathrm{N}(24)$ & $91.1(3)$ & $\mathrm{N}(11)-\mathrm{Ag}(4)-\mathrm{N}(71)$ & $100.0(3)$ \\
\hline $\mathrm{N}(61)-\mathrm{Ag}(2)-\mathrm{N}(31 \mathrm{~A})$ & $102.5(3)$ & $\mathrm{N}(71)-\mathrm{Ag}(4)-\mathrm{N}(54)$ & $104.0(3)$ \\
\hline $\mathrm{N}(81)-\mathrm{Ag}(2)-\mathrm{N}(61)$ & $139.3(3)$ & $\mathrm{N}(84)-\mathrm{Ag}(4)-\mathrm{N}(54)$ & $101.8(3)$ \\
\hline $\mathrm{N}(81)-\mathrm{Ag}(2)-\mathrm{N}(31 \mathrm{~A})$ & $111.7(2)$ & $\mathrm{N}(84)-\mathrm{Ag}(4)-\mathrm{N}(11)$ & $137.2(3)$ \\
\hline $\mathrm{N}(81)-\mathrm{Ag}(2)-\mathrm{N}(24)$ & $103.1(2)$ & $\mathrm{N}(84)-\mathrm{Ag}(4)-\mathrm{N}(71)$ & $111.5(3)$ \\
\hline \multicolumn{4}{|l|}{ Compound 2} \\
\hline $\mathrm{Cu}(1)-\mathrm{N}(1 \mathrm{~A})$ & $2.079(7)$ & $\mathrm{Cu}(2)-\mathrm{N}(2)$ & $2.018(3)$ \\
\hline $\mathrm{Cu}(1)-\mathrm{N}(3)$ & $2.046(3)$ & $\mathrm{Cu}(2)-\mathrm{N}(4)$ & $2.076(3)$ \\
\hline $\mathrm{Cu}(1)-\mathrm{O}(1)$ & $2.590(3)$ & $\mathrm{Cu}(2)-\mathrm{O}(2)$ & $2.424(3)$ \\
\hline $\mathrm{N}(1 \mathrm{~A})-\mathrm{Cu}(1)-\mathrm{N}(1 \mathrm{~A})$ & 180.0 & $\mathrm{~N}(4)-\mathrm{Cu}(2)-\mathrm{N}(4)$ & 180.0 \\
\hline $\mathrm{N}(1 \mathrm{~A})-\mathrm{Cu}(1)-\mathrm{O}(1)$ & $88.72(19)$ & $\mathrm{N}(4)-\mathrm{Cu}(2)-\mathrm{O}(2)$ & $91.15(1$ \\
\hline $\mathrm{N}(3)-\mathrm{Cu}(1)-\mathrm{N}(3)$ & 180.0 & $\mathrm{~N}(2)-\mathrm{Cu}(2)-\mathrm{N}(2)$ & 180.0 \\
\hline $\mathrm{N}(3)-\mathrm{Cu}(1)-\mathrm{N}(1 \mathrm{~A})$ & $89.5(2)$ & $\mathrm{N}(2)-\mathrm{Cu}(2)-\mathrm{N}(4)$ & $91.47(15)$ \\
\hline $\mathrm{N}(3)-\mathrm{Cu}(1)-\mathrm{O}(1)$ & $91.54(13)$ & $\mathrm{N}(2)-\mathrm{Cu}(2)-\mathrm{O}(2)$ & $87.84(13)$ \\
\hline $\mathrm{O}(1)-\mathrm{Cu}(1)-\mathrm{O}(1)$ & 180.0 & $\mathrm{O}(2)-\mathrm{Cu}(2)-\mathrm{O}(2)$ & 180.0 \\
\hline
\end{tabular}

comparison with the spectra simulated from the single crystal data of the two above species, showing that the mixture contains $c a .70 \%$ of $\mathbf{1}$ and $30 \%$ of the two-dimensional polymer. The crystals of $\mathbf{1}$ are air and light stable for long times and almost insoluble in all common organic solvents.

If compared with pyrazine (with a N-to-N distance of $c a$. $2.8 \AA$ ) the bis(4-pyridyl)ethane ligand is a much longer spacer (N-to-N of $c a .9 .3 \AA$ in the trans conformation), that has been extensively employed in the crystal engineering of coordination polymers, ${ }^{15}$ in order to obtain larger cavities and channels, suitable for containing guest molecules. The reaction of bpe with copper(II) sulfate in a molar ratio of $2: 1$ gives a bulk blue precipitate of composition $\left[\mathrm{Cu}(\mathrm{bpe})_{2}\left(\mathrm{SO}_{4}\right)\right] \cdot 5 \mathrm{H}_{2} \mathrm{O} 2$. Attempts to obtain single crystals of $\mathbf{2}$ upon layering an ethanolic solution of the ligand on a water solution of the metal salt, by slow diffusion of the reagents, resulted in the formation, together with the desired species, also of minor amounts of crystals of another product, characterized by X-ray diffraction as the $1: 1$ adduct $\left[\mathrm{Cu}(\mathrm{bpe})\left(\mathrm{SO}_{4}\right)\right] \cdot \mathrm{H}_{2} \mathrm{O}$. It contains - $\mathrm{Cu}-$ bpe-Cu-bpe- one-dimensional chains connected by bridging sulfate anions to form layers of squares. ${ }^{16}$ This species can be obtained as the unique product on performing the reaction with a $1: 1$ molar ratio of the reagents.

\section{Structure of the coesite-like species $\left[\mathrm{Ag}(2 \text {-ethpyz })_{2}\right]\left[\mathrm{SbF}_{6}\right] 1$}

The crystal structure of compound $\mathbf{1}$ contains a single threedimensional frame of four-connected silver ions linked by 2ethpyz spacer ligands, with the $\mathrm{SbF}_{6}{ }^{-}$anions occupying all the free voids of the network. There are four independent silver ions and eight independent 2-ethpyz ligands forming square subunits, as illustrated in Fig. 1. The co-ordination of the silver ions is quite distorted tetrahedral with $\mathrm{Ag}-\mathrm{N}$ bonds in the range 2.246(7)-2.525(8) $\AA$ and $\mathrm{N}-\mathrm{Ag}-\mathrm{N}$ angles ranging from $91.0(3)$ to $139.3(3)^{\circ}$ (see Table 1 ).

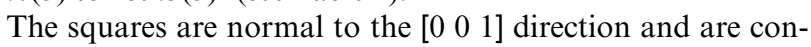

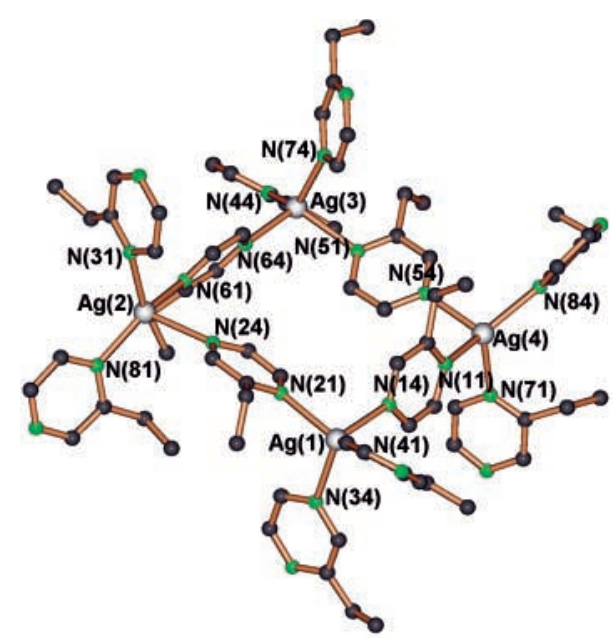

Fig. 1 A molecular square subunit of compound 1, with partial atomic labelling. Only the major components of the disordered ligands (see text) are shown for clarity.

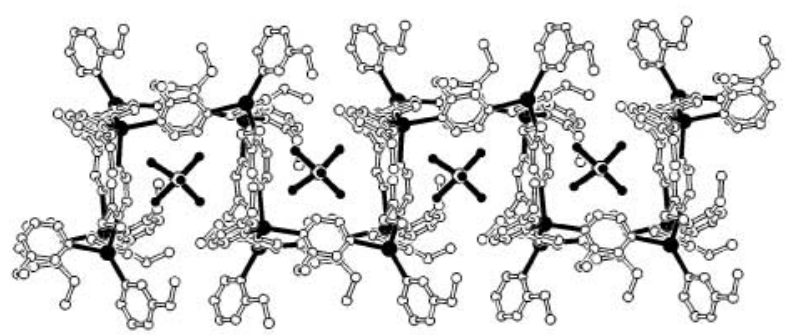

Fig. 2 A double-crankshaft ribbon of squares in compound 1. The $\mathrm{SbF}_{6}{ }^{-}$anions encapsulated in the pseudo-cubic boxes are also shown.

nected via four ligands, one per metal atom, to two equivalent square units lying one above and one below their molecular plane, to give one-dimensional ribbons extending along the direction of the $c$ crystallographic axis, as shown in Fig. 2. They can be seen as sequences of face-sharing incomplete 'cubic boxes' that encapsulate one class of $\mathrm{SbF}_{6}{ }^{-}$anions. The infinite ribbons of squares, called 'double-crankshafts' by O'Keeffe, ${ }^{10,17}$ represent basic topological motifs, common to other fourconnected nets (like feldspar), ${ }^{10,18}$ both in natural and in synthetic species, ${ }^{19,20}$ that are linked to identical parallel motifs by means of the remaining fourth ligand on each metal centre, to produce the overall three-dimensional architecture. Each double-crankshaft is connected to six parallel adjacent identical motifs, as schematically shown in Fig. 3. The network is binodal with a $\left(4^{2}, 6^{3}, 8\right)\left(4^{2}, 6,8^{2}, 9\right)$ topology (the first symbol for $\mathrm{Ag} 2$ and $\mathrm{Ag} 4$, the second one for $\mathrm{Ag} 1$ and $\mathrm{Ag} 3$ ), that is the same as the silicon net in the $\mathrm{SiO}_{2}$ high-pressure polymorph coesite. ${ }^{21}$ Compound $\mathbf{1}$ is, to our knowledge, the first example of a molecular based polymer with this topology. The topological properties of this net have been analysed by O'Keeffe, ${ }^{10,17}$ who underlined the presence of interpenetrating eightfold circuits.

The phenomenon is schematically rationalized in Fig. 4: starting from the view of the net approximately down $\left[\begin{array}{lll}1 & 0 & 1\end{array}\right]$ (Fig. 4, top) one can imagine cutting all the links along the planes indicated (that project as lines $\mathrm{AA}^{\prime}$ and $\mathrm{BB}^{\prime}$ ). The region isolated in this way is an infinite layer comprised of two interpenetrating two-dimensional nets of $\left(4,8^{2}\right)$ topology (Fig. 4, bottom). The self-catenation involves chains of edge-sharing eight-membered rings: pairs of such chains are interlocked as shown in Fig. 5.

\section{Structure of the nanoporous polymeric species $\left[\mathrm{Cu}(\mathrm{bpe})_{2}\left(\mathrm{SO}_{4}\right)\right]$. $5 \mathrm{H}_{2} \mathrm{O} 2$}

The crystal structure of compound $\mathbf{2}$ consists of a complex three-dimensional single network based on copper(II) centres 


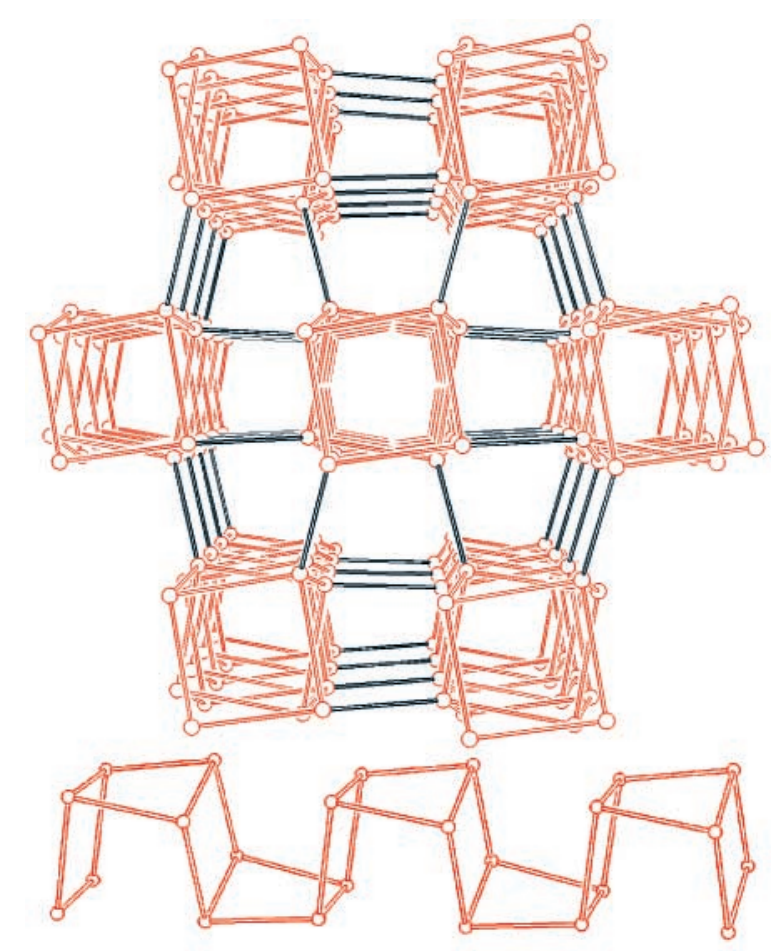

Fig. 3 Schematic views of a single ribbon (bottom) and of the overall array (top) derived by joining the ribbons in compound $\mathbf{1}$. The network is shown down the [llll $\left.\begin{array}{lll}0 & 0 & 1\end{array}\right]$ direction. All the channels (exhibiting distorted square section) contain rows of anions.
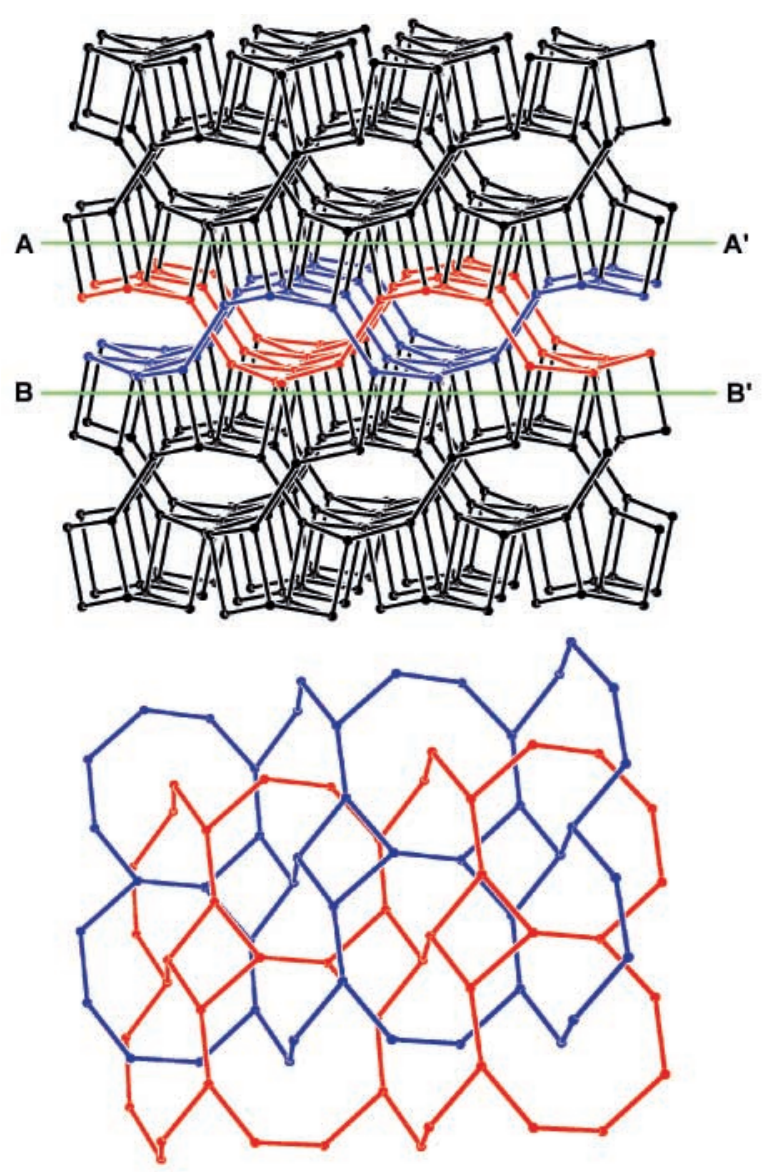

Fig. 4 Schematic rationalization of the self-interpenetration in compound 1: a section of the array, viewed down [1 011$]$ (top), can be isolated by breaking all the links along the planes indicated as AA $^{\prime}$ and $\mathrm{BB}^{\prime}$. This section corresponds to the 2-fold interpenetrated layer shown at the bottom with different colours for the two individual motifs, of $\left(4,8^{2}\right)$ topology.

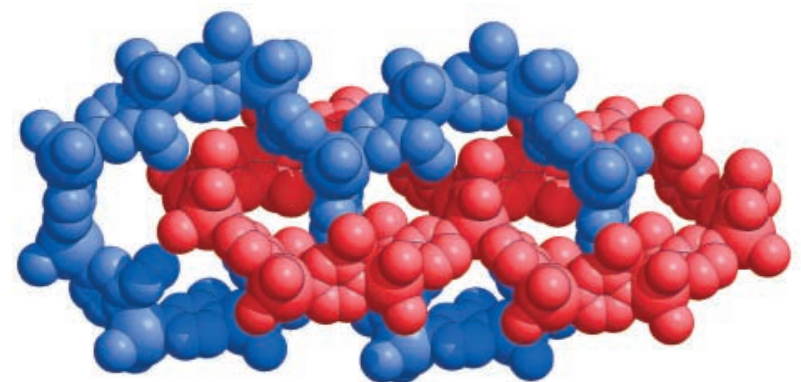

Fig. 5 Self-entanglement of two chains of eight-membered rings in compound 1.

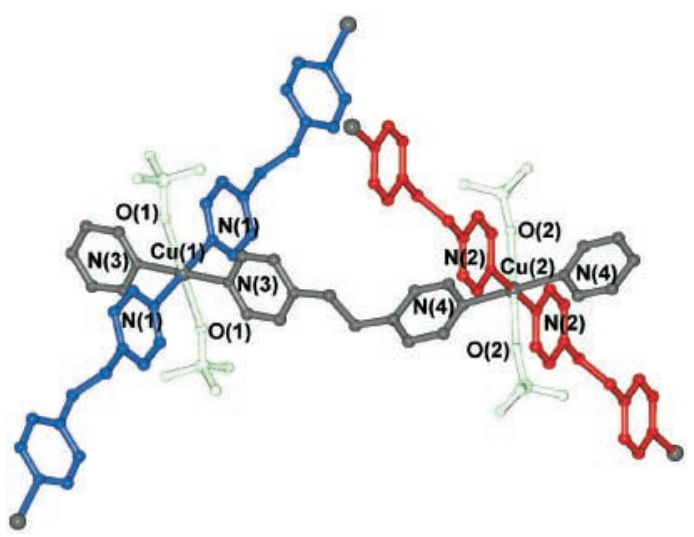

Fig. 6 The basic unit present in compound 2, showing the coordination spheres of the copper(II) atoms with partial labelling. Three different colours are used here and in the following diagrams to evidence the three independent bpe ligands: bpe1, blue; bpe2, red; bpe3, black.

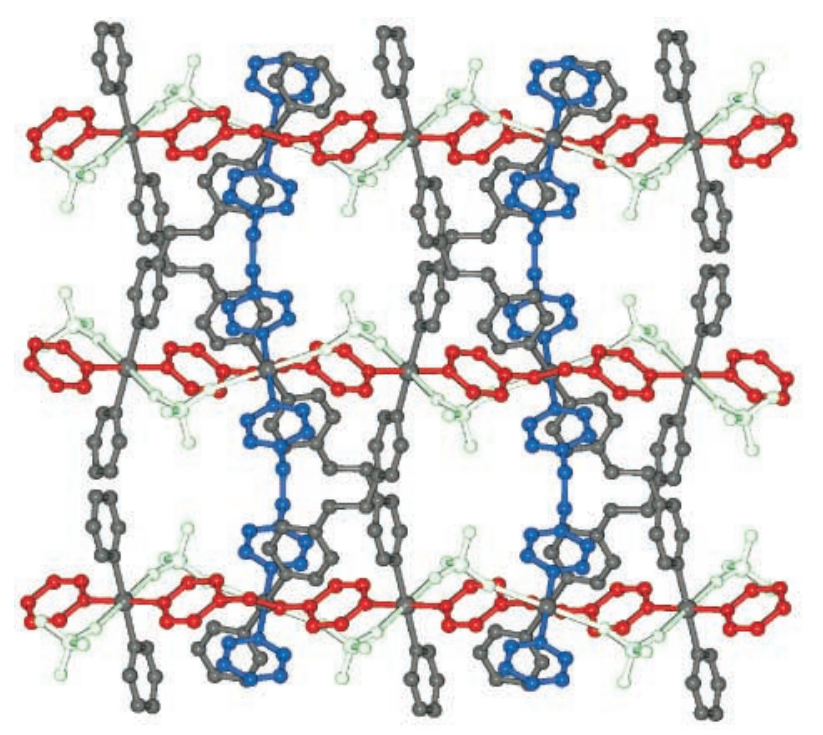

Fig. 7 A view down the $\left[\begin{array}{lll}1 & 0 & 0\end{array}\right]$ direction of the overall packing in compound 2.

four-connected to bpe spacer ligands. There are two independent copper atoms, lying on inversion centres, and three different bpe ligands, two of which (bpe1 and bpe2) are disposed about twofold axes. All the ligands exhibit the trans conformation, with N-to-N distances in the range 9.250-9.312 $\AA$. The metal atoms display octahedral $(4+2)$ co-ordination geometries, illustrated in Fig. 6, showing four equatorial bonds with pyridyl groups and two axial elongated interactions with oxygen atoms of the sulfates (see Table 1). The anions act as $\mu, \eta^{2}$ bridging between adjacent copper ions to give $-\mathrm{Cu} 1-\left(\mathrm{SO}_{4}\right)-\mathrm{Cu} 2-\left(\mathrm{SO}_{4}\right)-$ rows along the $\left[\begin{array}{lll}1 & 1 & 0\end{array}\right]$ and $\left[\begin{array}{lll}1 & -1 & 0\end{array}\right]$ directions. The overall packing is shown in Fig. 7. 


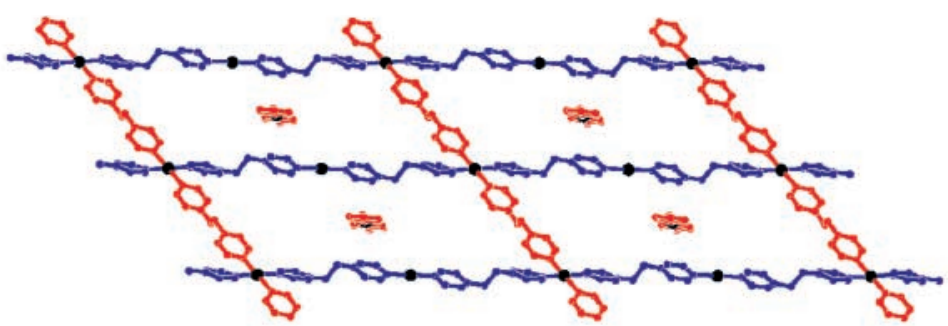

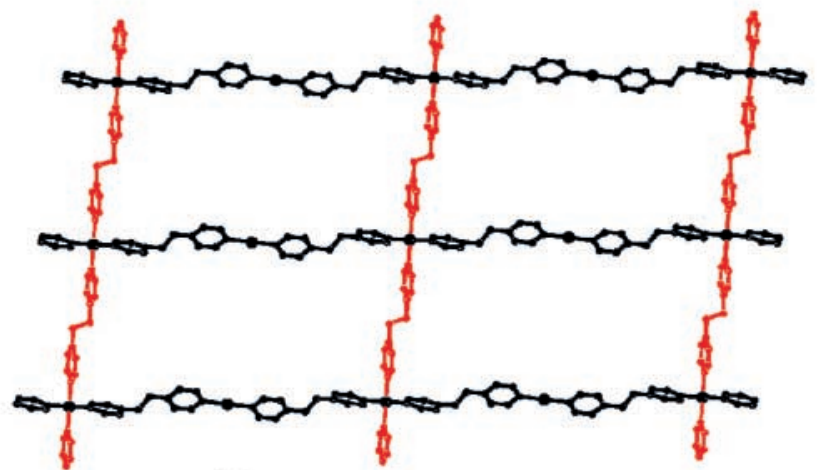

(b)

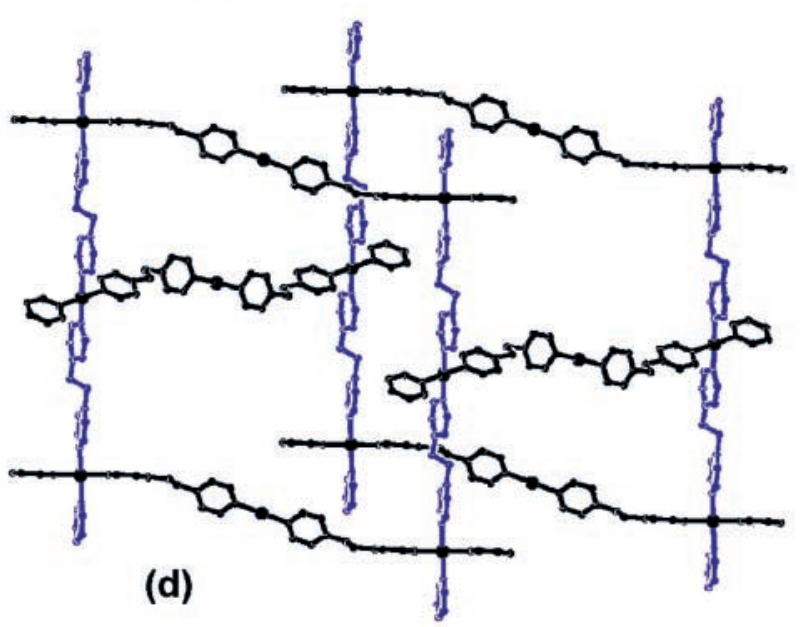

(a)
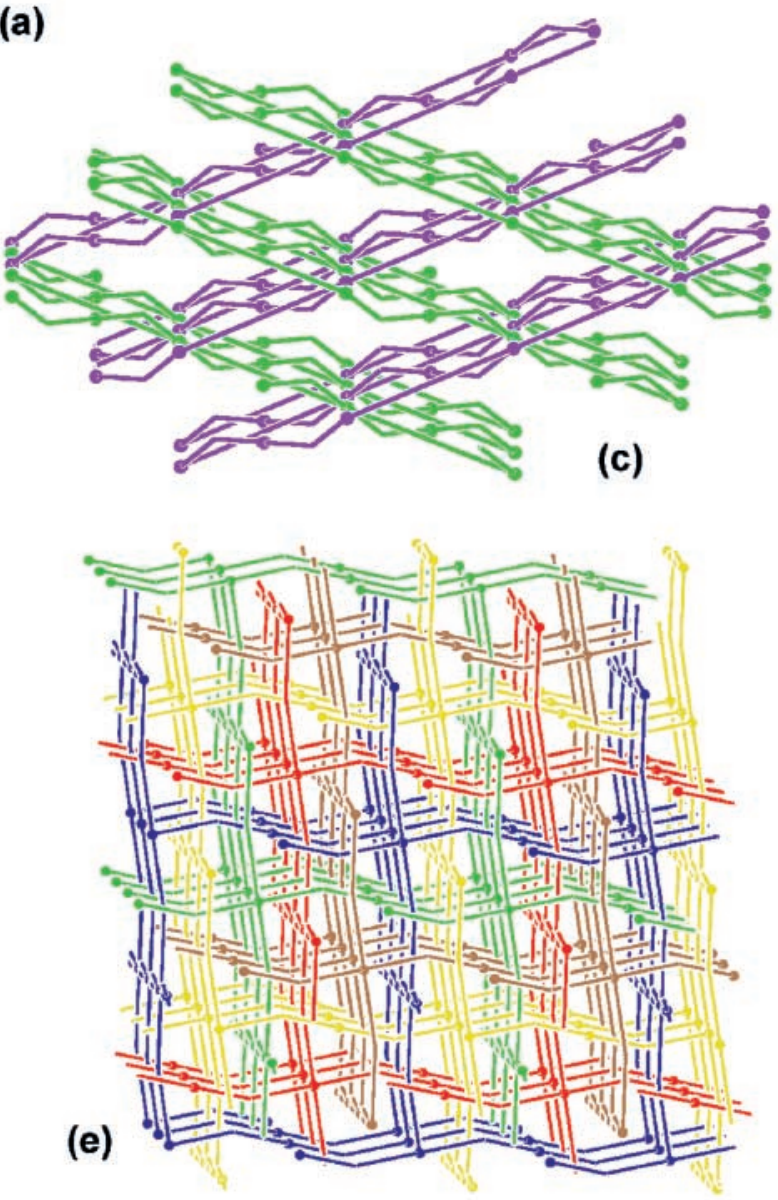

Fig. 8 A rationalization of the topology of the $\left[\mathrm{Cu}(\mathrm{bpe})_{2}\right]$ network in compound 2 : in (a) one can see the result of eliminating bpe3, that leaves onedimensional chains only, extending in three directions; in (b) the elimination of bpel gives two-dimensional layers of rectangles, that form two sets that show inclined interpenetration, as schematically illustrated in (c); in (d) the removal of bpe 2 leads to three-dimensional frames with the CdSO topology, that interpenetrate fivefold as schematically shown in (e).

Two of the bpe ligands connect only copper ions of the same type: the bpel ligands join the $\mathrm{Cu} 1$ ions into one-dimensional parallel chains all extending in the $\left[\begin{array}{lll}1 & 0 & -1\end{array}\right]$ direction (Cu1 ‥ Cu1 13.356 $\AA$ ), while the bpe 2 ligands connect the $\mathrm{Cu} 2$ ions to form chains spanning alternately the $\left[\begin{array}{lll}1 & -1 & 0\end{array}\right]$ and the $\left[\begin{array}{lll}1 & 1 & 0\end{array}\right]$ directions $(\mathrm{Cu} 2 \cdots \mathrm{Cu} 213.263 \AA)$. The third ligand,

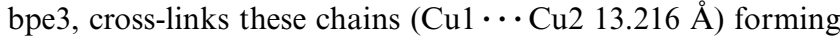
a three-dimensional $\left[\mathrm{Cu}(\mathrm{bpe})_{2}\right]$ network. This is a binodal fourconnected net with the, to our knowledge, unprecedented $\left(6^{4}, 8^{2}\right)\left(6,8^{5}\right)$ topology (the two corresponding nodes being $\mathrm{Cu} 2$ and $\mathrm{Cu} 1$, respectively). ${ }^{22}$

A better insight into the nature of this intricate architecture can be achieved if one can imagine removing one at a time the three independent bpe ligands (see Fig. 8). On removing the cross-linking bpe 3 ligands all the remainder is comprised of three types of one-dimensional chains spanning three different directions [Fig. 8(a)], one of which contains only $\mathrm{Cu} 1$ and the other two only $\mathrm{Cu} 2$, as mentioned above. Different intriguing polymeric motifs can be envisaged by eliminating bpe1 or bpe 2 : in the former case two-dimensional layers of rectangular grids [of $(4,4)$ topology] are obtained, with the $\mathrm{Cu} 2$ ions at the corners and the $\mathrm{Cul}$ ones as spacers in the middle of the longer edges [Fig. 8(b)]. The layers display two spatial orientations and give inclined interpenetration, as shown in Fig. 8(c). On the other hand, elimination of bpe 2 leaves a three-dimensional four-connected frame [Fig. 8(d)] with the $\mathrm{CdSO}_{4}$ topology $\left(6^{5}, 8\right),{ }^{10,23}$ exhibiting 5 -fold interpenetration [Fig. 8(e)]. The same topology has recently been observed in the threefold interpenetrated network of $\left[\mathrm{Cu}\left(\mathrm{NO}_{3}\right)_{2}(\mathrm{bpe})_{2}\right]{ }^{24}$ Since the subnets of compound $\mathbf{2}$ described above are interpenetrated the overall framework is self-interpenetrated or self-catenated. All the basic circuits (6- and 8-membered rings) are catenated by other circuits. The self-catenation of the 6-membered rings by other 6-membered rings, occurring at the intersection of the crossing of two-dimensional layers described above [see Fig. 8(c)], is illustrated in Fig. 9.

The reason for interpenetration is the need to fill the void space of a single network, i.e. a consequence of mother nature's horror vacui, and a similar role is played also by self-interpenetration. However, in spite of this feature, compound $\mathbf{2}$ is a nanoporous material that contains large cavities full of solvated water molecules (see Fig. 10). The overall free volume can be estimated to be about $1200 \AA^{3}$, i.e. $20.4 \%$ of the cell volume. The cavities are disposed to form continuous 


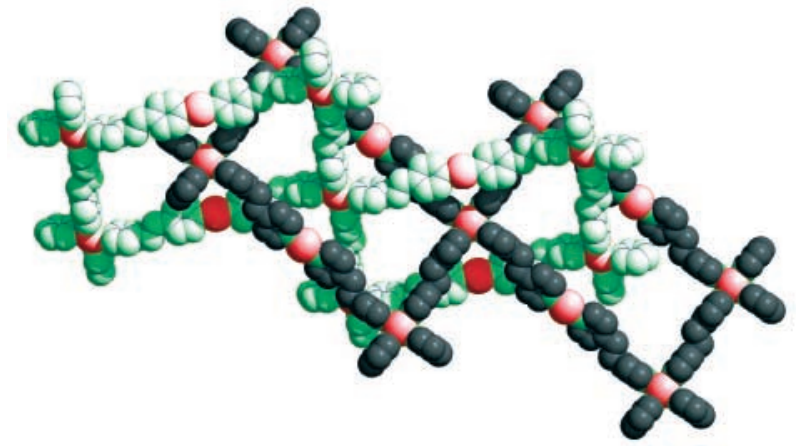

Fig. 9 The self-catenation of two chains of rectangular 6-membered circuits in compound 2
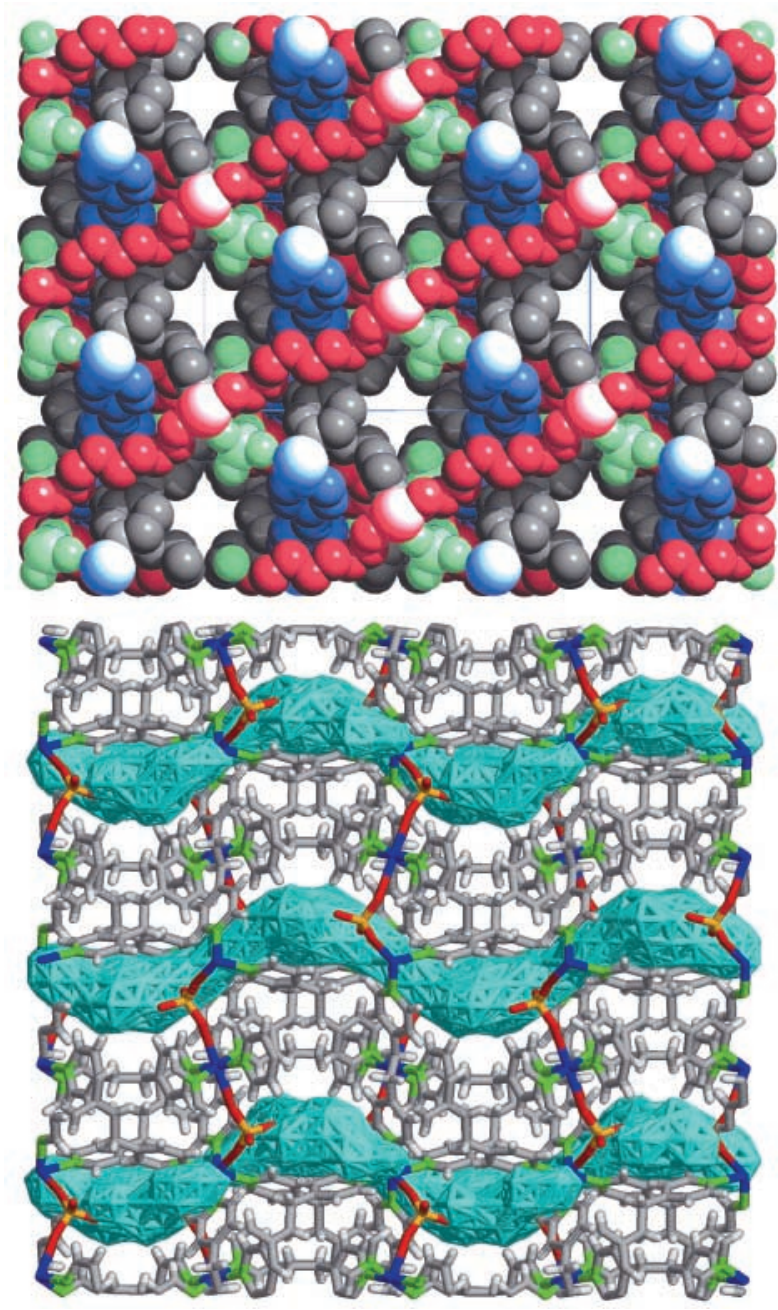

Fig. 10 On the top, a sphere packing view of compound 2 down the $\left[\begin{array}{lll}1 & 0 & 0\end{array}\right]$ direction, showing the channels that contain the solvated water molecules; on the bottom a lateral view of such channels, represented by their limiting surfaces.

snaking channels extending in the $\left[\begin{array}{lll}1 & 0 & 0\end{array}\right]$ direction, whose surfaces can be modelled as shown in Fig. 10 (bottom). ${ }^{25}$

Thermogravimetric analyses on powder samples of compound 2 show a weight loss of about $12 \%$ in the range 40 $120^{\circ} \mathrm{C}$, and DSC analyses exhibit an endothermic peak in the same range, that can be attributed to loss of the guest water molecules. The sample after desolvation is still crystalline and the X-ray powder diffraction pattern shows that the structure of the framework remains essentially unchanged. The process is reversible, as ascertained by TG analyses performed on a desolvated sample left for some hours exposed to water vapours. On increasing the temperature to $500{ }^{\circ} \mathrm{C}$ the $\mathrm{TG}$ analysis shows three further weight losses, of about 16 (range
120-200), $12(200-260)$ and $39 \%\left(260-420{ }^{\circ} \mathrm{C}\right)$. The residue at $500{ }^{\circ} \mathrm{C}$ is about $18 \%$ of the original weight and its XRPD pattern shows that the composition is $\mathrm{Cu}_{2} \mathrm{O}$ and metallic copper. The DSC analysis in the same range of temperature confirms the complex multistep way of decomposition. Monitoring by XRPD shows that in the range $140-180^{\circ} \mathrm{C}$ the sample is amorphous but at $c a .180^{\circ} \mathrm{C}$ it again becomes crystalline, with a different pattern.

\section{Conclusion}

The two polymeric species reported here contain $\left[\mathrm{ML}_{2}\right]$ threedimensional single networks that are noteworthy for their topology and for the feature of self-interpenetration. Both frames contain metal centres that are four-connected to the aromatic spacer ligands, with tetrahedral (in 1) or squareplanar (in 2) geometries. However, instead of the prototypical reference networks that are expected to be more probable with these types of centres, i.e. diamond and $\mathrm{NbO}$ (or also $\mathrm{CdSO}_{4}$ ), for $\mathbf{1}$ and $\mathbf{2}$ respectively, both polymers adopt uncommon topologies. In the former case, as already pointed out, the anions and the substituents on the pyrazine ring play a relevant but subtle role in orienting the overall structural motif, taking into account that the related polymer [bis(2,5-dimethylpyrazine)silver hexafluorophosphate, for example, consists of a single diamondoid net. ${ }^{26}$ The formation of a network like that in 1, that contains 'strained' square circuits, is also made possible thanks to the versatility of the silver ions in giving quite distorted co-ordination geometries. The topology of $\mathbf{2}$, when compared with that of the related species $\left[\mathrm{Cu}\left(\mathrm{NO}_{3}\right)_{2}-\right.$ (bpe $\left.)_{2}\right],^{24}$ of the $\mathrm{CdSO}_{4}$ topological type, can very probably be ascribed to the change of the counter ions and to the more pronounced ability of the sulfates to act as bridges between two metal centres.

The finding of new topologies can be useful at the basic level in the crystal engineering of co-ordination networks. The control of the topology is fundamental in determining the properties and applications of a networked material, by tuning the shape and dimensions of the cavities and channels. Generally the presence of interpenetration is a factor that limits the nanoporous behaviour of a species, and must be avoided for that purpose. The two examples reported here illustrate another factor that can operate in a similar sense, the rare phenomenon of self-catenation, that is expected to be encountered more frequently in the future with increasing number of structurally characterized networks. Though it represents a very fascinating structural feature, it certainly works in the sense of reducing the free voids inside a three-dimensional array, and, indeed, the self-catenated coesite is the densest known form of silica. ${ }^{21,27}$

\section{Experimental}

\section{Materials}

All reagents and solvents employed were commercially available high-grade purity materials (Aldrich Chemicals), used as supplied, without further purification. Elemental analyses were carried out at the Microanalytical Laboratory of the University of Milano. Thermal analyses were performed on Perkin-Elmer DSC 7 and TGA 7 at a heating rate of $10^{\circ} \mathrm{C} \mathrm{min}^{-1}$, under a flux of nitrogen. X-Ray powder diffraction patterns were collected on a Rigaku D/Max horizontal-scan diffractometer.

\section{Syntheses}

[Ag(2-ethpyz) $\left.)_{2}\right]\left[\mathrm{SbF}_{6}\right]$ 1. A solution of $\mathrm{AgSbF}_{6}(0.070 \mathrm{~g}$; $0.020 \mathrm{mmol})$ in ethanol $(2 \mathrm{~mL})$ was added to a solution of 2-ethylpyrazine $(0.044 \mathrm{~mL} ; 0.04 \mathrm{mmol})$ in $\mathrm{CH}_{2} \mathrm{Cl}_{2}(3 \mathrm{~mL})$. After stirring the reaction mixture for about $1 \mathrm{~h}$ it was left for many days in the dark and allowed to concentrate by slow evaporation in the air, to give in good yield a crystalline pre- 
Table 2 Crystal data and structure refinement parameters for compounds 1 and 2

\begin{tabular}{lll}
\hline & $\mathbf{1}$ & $\mathbf{2}$ \\
\hline Formula & $\mathrm{C}_{12} \mathrm{H}_{16} \mathrm{AgF}_{6} \mathrm{~N}_{4} \mathrm{Sb}$ & $\mathrm{C}_{24} \mathrm{H}_{34} \mathrm{CuN}_{4} \mathrm{O}_{9} \mathrm{~S}$ \\
$M$ & 559.91 & 618.15 \\
Crystal system & Monoclinic & Monoclinic \\
Space group & $C c$ (no. 9$)$ & $C 2 / c($ no. 15$)$ \\
$a / \AA$ & $16.970(1)$ & $13.057(1)$ \\
$b / \AA$ & $29.369(2)$ & $23.092(3)$ \\
$c / \AA$ & $16.552(1)$ & $19.966(2)$ \\
$\beta /{ }^{\circ}$ & $116.02(1)$ & $106.10(1)$ \\
$U / \AA^{3}$ & $7413.1(8)$ & $5784.0(10)$ \\
$Z$ & 16 & 8 \\
$\mu /$ mm & & 0.882 \\
Reflections collected & 2.572 & 34404 \\
Unique reflections, $R_{\text {int }}$ & 41931 & $8200,0.0644$ \\
Observed reflections & $13079,0.0261$ & 4954 \\
$\quad 1 I>2 \sigma(I)]$ & 10296 & \\
Final $R 1, w R 2$ & & \\
$\quad$ (observed data) & $0.0466,0.1253$ & \\
\hline
\end{tabular}

cipitate that was recovered by filtration and dried in the air. This precipitate contains beautiful large colourless crystals of complex 1 together with minor amounts of a second crystalline species, that was shown to be $\left[\mathrm{Ag}_{2}(2-\text { ethpyz })_{3}\right]\left[\mathrm{SbF}_{6}\right]_{2}$ by structure analysis. The crystals of $\mathbf{1}$ were separated under a microscope and submitted to elemental analysis. Calc. for $\mathrm{C}_{12} \mathrm{H}_{16} \mathrm{AgF}_{6} \mathrm{~N}_{4} \mathrm{Sb}: \mathrm{C}, 25.74 ; \mathrm{H}, 2.88 ; \mathrm{N}, 10.01$. Found: C, 25.20; $\mathrm{H}, 2.90 ; \mathrm{N}, 9.95 \%$.

[Cu(bpe $\left.)_{2}\left(\mathbf{S O}_{4}\right)\right] \cdot 5 \mathrm{H}_{2} \mathrm{O}$ 2. A solution of 1,2-bis(4-pyridyl)ethane $(0.110 \mathrm{~g}, 0.597 \mathrm{mmol})$ in $\mathrm{EtOH}(4 \mathrm{~mL})$ was added to a stirred solution of $\mathrm{CuSO}_{4} \cdot 5 \mathrm{H}_{2} \mathrm{O}(0.0665 \mathrm{~g}, 0.266 \mathrm{mmol})$ in water $(3 \mathrm{~mL})$ at room temperature. A blue precipitate was formed immediately. The reaction mixture was left to stir for $2 \mathrm{~h}$, then the precipitate was recovered by filtration and dried in the air (yield $>85 \%$ ). The pure nature of these powdered samples has been confirmed by $\mathrm{X}$-ray powder diffraction methods. Calc. for $\mathrm{C}_{24} \mathrm{H}_{34} \mathrm{CuN}_{4} \mathrm{O}_{9} \mathrm{~S}$ : C, 46.63; H, 5.54; N, 9.06. Found: C, 46.75; H, 5.41; N, 9.20\%. Single crystals suitable for structural analysis were obtained by slow diffusion of an ethanolic solution of bpe on an aqueous solution of the copper salt in the molar ratio $2: 1$.

\section{Crystallography}

Crystal data for compounds $\mathbf{1}$ and $\mathbf{2}$ are in Table 2. The data collections were performed at $293 \mathrm{~K}$ on a SMART-CCD Bruker diffractometer, by the $\omega$-scan method, within the limits $2<\theta<24$ (1), $2<\theta<30^{\circ}(2)$. Empirical absorption corrections $(\mathrm{SADABS})^{28}$ were applied in both cases. The structures were solved by direct methods (SIR 97) ${ }^{29}$ and refined by full-matrix least squares on $F^{2}$ (SHELX 97). ${ }^{30}$

In compound 1 one of eight independent ligands was found disordered and refined isotropically using two models with occupancies of 60 and $40 \%$. Another ligand displays disorder involving only the terminal methyl group. Also two $\mathrm{SbF}_{6}$ anions are disordered and their refinements were carried out isotropically, using a suitable double model for each. Anisotropic thermal parameters were assigned to all the other nonhydrogen atoms but the fluorine atoms. In 2 one of the bpe ligands, lying about a twofold axis, shows disorder and was treated isotropically using two models with refined occupancies of $55-45 \%$. Anisotropic thermal parameters were assigned to all non-hydrogen atoms except to the oxygen atoms of the clathrate water molecules. All the diagrams were drawn using the SCHAKAL 99 program. ${ }^{31}$

CCDC reference number 186/2038.

See http://www.rsc.org/suppdata/dt/b0/b003092i/ for crystallographic files in .cif format.

\section{References}

1 B. F. Hoskins and R. Robson, J. Am. Chem. Soc., 1990, 112, 1546; R. Robson, B. F. Abrahams, S. R. Batten, R. W. Gable, B. F. Hoskins and J. Liu, in Supramolecular Architecture, American Chemical Society, Washington, DC, 1992, ch. 19; M. J. Zaworotko, Chem. Soc. Rev., 1994, 283; C. L. Bowes and G. A. Ozin, Adv. Mater., 1996, 8, 13; O. M. Yaghi, H. Li, C. Davis, D. Richardson and T. L. Groy, Acc. Chem. Res., 1998, 31, 474; M. Munakata, L. P. Wu and T. Kuroda-Sowa, Adv. Inorg. Chem., 1999, 46, 173; P. J. Hagrman, D. Hagrman and J. Zubieta, Angew. Chem., Int. Ed., 1999, 38, 2638; A. J. Blake, N. R. Champness, P. Hubberstey, W. S. Li, M. A. Withersby and M. Schröder, Coord. Chem. Rev., 1999, 183, 117.

2 See e.g.: C. Janiak, Angew. Chem., Int. Ed. Engl., 1997, 36, 1431; C. J. Kepert and M. J. Rosseinsky, Chem. Commun., 1998, 31; D. M. L. Goodgame, D. A. Grachvogel and D. J. Williams, Angew. Chem., Int. Ed., 1999, 38, 153; L. Carlucci, G. Ciani, M. Moret, D. M. Proserpio and S. Rizzato, Angew. Chem., Int. Ed., 2000, 39, 1506.

3 See e.g.: (a) L. Carlucci, G. Ciani, P. Macchi and D. M. Proserpio, Chem. Commun., 1998, 1837; (b) B. F. Abrahams, S. R. Batten, M. J. Grannas, H. Hamit, B. F. Hoskins and R. Robson, Angew. Chem., Int. Ed., 1999, 38, 1475

4 There is a renewed interest within the scientific community for the enumeration/classification of three-dimensional networks (see e.g. : U. Müller, Angew. Chem., Int. Ed., 2000, 39, 502 and refs. therein; O. Delgado Friedrichs, A. W. M. Dress, D. H. Huson, K. Klinowski and A. L. Mackay, Nature (London), 1999, 400, 644). There are, at present, different approaches and notations, including those of the older works by Wells (see ref. 8) and of the more recent contributions by O'Keeffe (see refs. 10 and 17), that still need to be integrated. We are currently using the O'Keeffe/Wells notation with Schläfli symbols.

5 S. R. Batten and R. Robson, Angew. Chem., Int. Ed., 1998, 37, 1460.

6 B. F. Hoskins, R. Robson and D. A. Slizys, J. Am. Chem. Soc., 1997, 119, 2952.

7 See e.g.: M. Fujita, Y. J. Kwon, O. Sasaki, K. Yamaguchi and K. Ogura, J. Am. Chem. Soc., 1995, 117, 7287; A. J. Blake, N. R. Champness, A. Khlobystov, D. A. Lenenovkii, W.-S. Li and M. Schröder, Chem. Commun., 1997, 2027; L. Carlucci, G. Ciani and D. M. Proserpio, J. Chem. Soc., Dalton Trans., 1999, 1799; F.-Q. Liu and T. D. Tilley, Inorg. Chem., 1997, 36, 5090; L. Carlucci, G. Ciani, P. Macchi, D. M. Proserpio and S. Rizzato, Chem. Eur. J., 1999, 5, 237; M.-L. Tong, X.-M. Chen, B.-H. Ye and L.-N. Ji, Angew. Chem., Int. Ed., 1999, 38, 2237.

8 A. F. Wells, Further Studies of Three-dimensional Nets, ACA Monograph No. 8, American Crystallographic Association, Pittsburg, OH, 1979; Three-dimensional Nets and Polyhedra, J. Wiley \& Sons, New York, 1977.

9 M. A. Withersby, A. J. Blake, N. R. Champness, P. A. Cooke, P. Hubberstey and M. Schröder, J. Am. Chem. Soc., 2000, 122, 4044. In this case the self-entangled frame is not based exclusively on coordinative bonds but arises from the interactions of the anions connecting the ladders. Obviously, this example can be generalized since any $n$-fold interpenetrated motif can give rise to a unique selfentangled array by joining the independent frames with bridging groups.

10 M. O'Keeffe and B. G. Hyde, Crystal Structures I. Patterns and Symmetry, Mineralogical Society of America, Washington, DC, 1996; M. O'Keeffe, M. Eddaoudi, H. Li, T. Reineke and O. M. Yaghi, J. Solid State Chem., 2000, 152, 3.

11 L. Carlucci, G. Ciani, D. M. Proserpio and A. Sironi, J. Am. Chem. Soc., 1995, 117, 4562 .

12 L. Carlucci, G. Ciani, D. M. Proserpio and A. Sironi, Angew. Chem., Int. Ed. Engl., 1995, 34, 1895.

13 L. Carlucci, G. Ciani, D. M. Proserpio and A. Sironi, Chem. Commun., 1996, 1393.

14 Crystal data for $\left[\mathrm{Ag}_{2}(2 \text {-ethpyz })_{3}\right]\left[\mathrm{SbF}_{6}\right]_{2}$ : monoclinic, space group $P 2_{1}$ (no. 4), $a=8.634(2), b=16.043(3), c=22.164(4) \quad \AA, \quad \beta=$ 91.42(2) $, V=3069.1(11) \AA^{3}, Z=4$. L. Carlucci, G. Ciani, D. M. Proserpio and $\mathrm{S}$. Rizzato, unpublished results.

15 M. Fujita, Y. J. Kwon, M. Miyazawa and K. Ogura, J. Chem. Soc., Chem. Commun., 1994, 1977; T. L. Hennigar, D. C. MacQuarrie, P. Losier, R. D. Rogers and M. J. Zaworotko, Angew. Chem., Int. Ed. Engl., 1997, 36, 972; M. L. Hernández, M. C. Barandika, M. K. Urtiaga, R. Cortéz, L. Lezama and M. I. Arriortua, J. Chem. Soc., Dalton Trans., 2000, 79.

16 Crystal data for $\left[\mathrm{Cu}(\mathrm{bpe})\left(\mathrm{SO}_{4}\right)\right] \cdot \mathrm{H}_{2} \mathrm{O}$ : triclinic, space group $P \overline{1}$ (no. 2), with $a=9.406(3), b=9.501(2), c=10.084(3) \AA, a=62.11(2)$, $\beta=89.19(3), \quad \gamma=73.05(2)^{\circ}, \quad V=753.9(4) \AA^{3}, Z=2$. L. Carlucci, G. Ciani, D. M. Proserpio and S. Rizzato, unpublished results. 
17 M. O'Keeffe, Z. Kristallogr., 1991, 196, 21.

18 J. V. Smith, Am. Mineral., 1978, 63, 960.

19 The only previous example of a mineralomimetic co-ordination polymer with double-crankshaft subunits and the topology of paracelsian has been reported by S. W. Keller, Angew. Chem., Int. Ed. Engl., 1997, 36, 247.

$20 \mathrm{~A}$ recent report of synthetic zeolite-like networks with doublecrankshaft subunits, exhibiting the gismondine and a pseudofeldspar $\left[\left(4^{3}, 6^{2}, 8\right)\left(4^{2}, 6^{3}, 8\right)\right]$ topology can be found in: R. Kniep, G. Schäfer, H. Engelhardt and I. Boy, Angew. Chem., Int. Ed., 1999, 38, 3641 .

21 G. V. Gibbs, C. T. Prewitt and K. J. Baldwin, Z. Kristallogr., 1977, 145, 108.

22 Taking into account also the sulfates the overall array must be described as a self-interpenetrated 6-connected network of very complex topology.

23 O. M. Yaghi, H. Li and M. O'Keeffe, Mater. Res. Soc. Symp. Proc., 1997, 453, 127.
24 K. N. Power, T. L. Hennigar and M. J. Zaworotko, Chem. Commun., $1998,595$.

25 An analysis of the holes was performed with the PLATON program: A. L. Spek, PLATON, A Multipurpose Crystallographic Tool, Utrecht University, 1999. The graphic representation of the surfaces of the cavities was obtained with SURFNET: R. A. Laskowski, J. Mol. Graph., 1995, 13, 323.

26 L. Carlucci, G. Ciani, D. M. Proserpio and S. Rizzato, to be published.

27 F. Liebau, Structural Chemistry of Silicates, Springer-Verlag, Berlin, 1985.

28 G. M. Sheldrick, SADABS, Siemens Area Detector Absorption Correction Software, University of Göttingen, 1996.

29 A. Altomare, M. C. Burla, M. Camalli, G. Cascarano, C. Giacovazzo, A. Guagliardi, A. G. Moliterni, G. Polidori and R. Spagna, J. Appl. Crystallogr., 1999, 32, 115.

30 G. M. Sheldrick, SHELX 97, University of Göttingen, 1997.

31 E. Keller, SCHAKAL 99, University of Freiburg, 1999. 